\title{
Hepatitis C Virus and Antiviral Drug Resistance
}

\author{
Seungtaek Kim, Kwang-Hyub Han, and Sang Hoon Ahn \\ Institute of Gastroenterology, Department of Internal Medicine, Yonsei University College of Medicine, Seoul, Korea
}

Since its discovery in 1989, hepatitis C virus (HCV) has been intensively investigated to understand its biology and develop effective antiviral therapies. The efforts of the previous 25 years have resulted in a better understanding of the virus, and this was facilitated by the development of in vitro cell culture systems for HCV replication. Antiviral treatments and sustained virological responses have also improved from the early interferon monotherapy to the current all-oral regimens using direct-acting antivirals. However, antiviral resistance has become a critical issue in the treatment of chronic hepatitis $\mathrm{C}$, similar to other chronic viral infections, and retreatment options following treatment failure have become important questions. Despite the clinical challenges in the management of chronic hepatitis $\mathrm{C}$, substantial progress has been made in understanding $\mathrm{HCV}$, which may facilitate the investigation of other closely related flaviviruses and lead to the development of antiviral agents against these human pathogens. (Gut Liver 2016;10:890-895)

Key Words: Hepatitis C virus; Direct-acting antiviral; Drug resistance

\section{INTRODUCTION}

Hepatitis C virus (HCV) infects approximately 130 to 170 million people worldwide and the infected patients suffer from chronic hepatitis, cirrhosis, and hepatocellular carcinoma. Most of HCV infection (70\% to 80\%) becomes chronic and has been a tremendous burden on the public health. The HCV infection was first known as non-A, non-B hepatitis (NANBH) ${ }^{1,2}$ and the causative agent of this NANBH was identified as hepatitis $\mathrm{C}$ virus in $1989 .^{3}$ Since then, substantial progresses in the knowledge of HCV virology, development of research tools, and drug discovery have been made and now new antiviral therapies based on all-oral regimens are beginning to be used. A few notable accomplishments in HCV virology include the development of replicon system ${ }^{4}$ and JFH1 cell culture-infectious clone, ${ }^{5}$ which enabled screening of small molecule libraries for drug discovery as well as investigating all the steps of HCV life cycle including virus assembly and secretion.

\section{VIROLOGY}

HCV is an enveloped, positive-strand RNA virus and belongs to the genus Hepacivirus within the family Flaviviridae (for a comprehensive review of HCV virology, see Lemon et al. $\left.{ }^{6}\right)$. The RNA genome of this virus is approximately $9.6 \mathrm{~kb}$ long and encodes a single polyprotein by the internal ribosome entry site-dependent translation (Fig. 1). The polyprotein $(\sim 3,000$ amino acids) is co- and post-translationally processed by both virus and host proteases to generate a total of 10 viral proteins (N terminus-Core-E1-E2-p7-NS2-NS3-NS4A-NS4B-NS5ANS5B-C terminus). The three proteins (Core, E1, and E2) at the $\mathrm{N}$ terminus are the structural proteins that are directly involved in the formation of virions while the rest at the $\mathrm{C}$ terminus (p7, NS2, NS3, NS4A, NS4B, NS5A, and NS5B) are the nonstructural proteins. Briefly, the core protein is a component of viral capsid and E1, E2 proteins are envelope glycoproteins that mediate the hepatocyte-specific entry of HCV virions. Nonstructural proteins are involved in many aspects of HCV life cycle including viral genome replication. p7 protein is known as an ion channel protein (viroporin) and NS2 protein is a cysteine autoprotease, which catalyzes the cleavage between NS2 and NS3 protein. Both p7 and NS2 proteins are also known to be involved in virus assembly process. The proteins from NS3 to NS5B (NS3NS4A-NS4B-NS5A-NS5B) are indispensable for viral RNA replication as the major components of the replication complex. ${ }^{4}$ NS3 protein contains two enzymatic activities: serine protease

\footnotetext{
Correspondence to: Seungtaek Kim ${ }^{\mathrm{a}}$ and Sang Hoon $\mathrm{Ahn}^{\mathrm{b}}$

Institute of Gastroenterology, Department of Internal Medicine, Yonsei University College of Medicine, 50-1 Yonsei-ro, Seodaemun-gu, Seoul 03722, Korea

${ }^{\mathrm{a}}$ Tel: +82-2-2228-0843, Fax: +82-2-2227-8129, E-mail: kimst@yuhs.ac

${ }^{\text {b}}$ Tel: +82-2-2228-1936, Fax: +82-2-393-6884, E-mail: ahnsh@yuhs.ac

Received on November 10, 2015. Revised on December 15, 2015. Accepted on December 29, 2015.

pISSN 1976-2283 eISSN 2005-1212 https://doi.org/10.5009/gnl15573

() This is an Open Access article distributed under the terms of the Creative Commons Attribution Non-Commercial License (http://creativecommons.org/licenses/by-nc/4.0) which permits unrestricted non-commercial use, distribution, and reproduction in any medium, provided the original work is properly cited.
} 


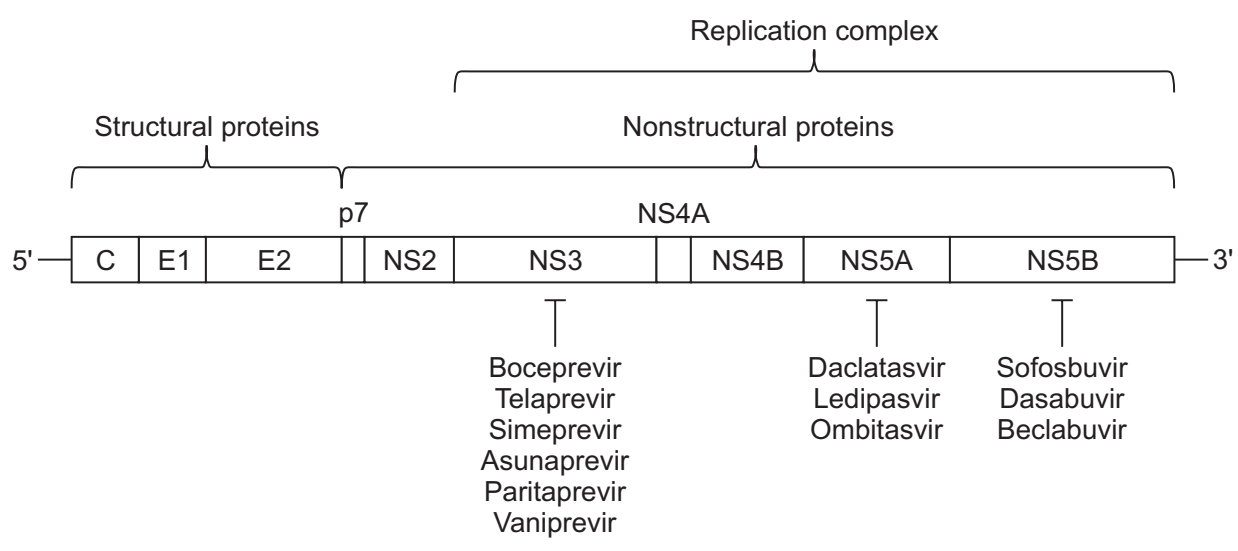

Fig. 1. Hepatitis $C$ virus genome structure. Internal ribosome entry site-mediated translation of viral RNA generates a single polyprotein, which is co- and post-translationally processed by host and viral proteases to produce 10 viral proteins. Core (C), E1 and E2 envelope glycoproteins are the structural proteins, and the remaining proteins represent nonstructural proteins. The replication complex comprises NS3 to NS5B proteins within the membranous web structure near the endoplasmic reticulum membrane. and helicase. The protease activity of NS3 cleaves the viral proteins of the polyprotein from NS3 to NS5B, while the helicase activity is involved in viral assembly. NS4A protein is a cofactor of NS3 protein and helps NS3 protein associate with the cellular membrane. NS4B protein is known to generate membranous web structures near the ER membrane of the host cell, which are thought to be the place where RNA replication occurs. NS5A protein does not have any known enzymatic activity but is important for both viral RNA replication and infectious virus assembly. Finally, NS5B is an RNA-dependent RNA polymerase that synthesizes plus- and minus-strand of viral RNAs. Among these viral proteins, NS3, NS5A, and NS5B proteins are the major targets of direct-acting antivirals (DAAs) and currently several DAAs are being used for treatment of chronic hepatitis C (Fig. 1).

\section{Virus life cycle}

Overall, the life cycle of HCV is similar to those of other positive-strand RNA viruses. The virus enters the hepatocyte via the receptor-mediated endocytosis (for an updated, comprehensive review of HCV entry, see Ding et al. ${ }^{7}$ ). After fusion and uncoating of the virion within the cell, the viral genome is released into the cytoplasm. Since the viral genome is positive-sense, it is directly used as mRNA for translation of the viral polyprotein. Several viral proteins (NS3 to NS5B) after cleavage and processing of the viral polyprotein are recruited to the membranous web to make replication complexes. Within this replication complex, the viral genome replication occurs (for an updated, comprehensive review of HCV RNA replication and assembly, see Paul et al. ${ }^{8}$ ): a negative-strand RNA is synthesized first using the positive-strand viral RNA and then multiple copies of positive-strand RNA are synthesized using the negative-strand viral RNA. The structural proteins and the positive-strand viral RNA are then assembled to produce infectious virus particles near the lipid droplets ${ }^{9}$ and the infectious virus particles are released out of the cell using the host VLDL-secretory pathway. ${ }^{10,11}$

\section{Systems for studying HCV}

Development of in vitro cell culture system for HCV replication is indispensable for HCV research and drug discovery. The first replicon system, that supports HCV genome replication when its RNA is transfected into the Huh7 hepatoma cells, was reported in 1999. ${ }^{4}$ This replicon system used the genotype $1 \mathrm{~b}$ Con 1 isolate and currently the replicon systems are available for most of the HCV genotypes. ${ }^{12-18}$ While the replicon system is useful for studying viral genome replication, it does not support the production of infectious virus particles. In 2003, the functional HCV pseudoparticle system (HCVpp) was described. ${ }^{19}$ The virus that is produced by this system is in fact a retrovirus, but is coated with HCV envelope glycoproteins, E1 and E2, thus the infection by the HCVpp generally follows the steps of the specific HCV entry pathway. By incorporating the sequence of reporter genes such as green fluorescent protein or luciferase, the virus entry can be monitored either visually or quantitatively without further complications due to the viral genome replication. Finally, the first cell culture-infectious clone (HCVcc), which can recapitulate the entire viral life cycle of HCV in cell culture, was established in 2005 using the genotype 2a JFH1 isolate. ${ }^{5}$ This virus was unique in that its RNA was able to replicate efficiently in Huh7 hepatoma cells without any cell culture-adaptive mutations, which were indispensable for other replicons to replicate in the in vitro cell culture system. When the JFH1 RNA was transfected into the Huh7 hepatoma cells, the transfected cells supported the production of infectious virus particles as well as the efficient RNA replication. The produced virus particles could then infect animal models such as chimpanzee and naïve hepatoma cells, thus completing an entire viral life cycle. This system can be used for investigation of all the steps of viral life cycle, specifically virus assembly and secretion steps. The HCVcc system is currently available for the genotypes 1a, 2a, and $3 \mathrm{a}^{5,20-23}$ 


\section{TREATMENT OF CHRONIC HEPATITIS C}

Since the description of NANBH, treatment of chronic hepatitis $\mathrm{C}$ has evolved from the nonspecific antiviral treatment using interferon to the all-oral regimens using DAAs. ${ }^{24}$ In the late 1990s, the interferon monotherapy for the treatment of chronic hepatitis $\mathrm{C}$ patients was modified by the addition of ribavirin, a nucleoside analog, which increased the sustained virological response (SVR) by 20\% compared to the interferon monotherapy. ${ }^{25}$ And later, pegylation of interferon (pegIFN) was demonstrated more effective than nonpegylated interferon by an increase of SVR of $10 \%$ to $15 \% .{ }^{26,27}$ Thus, until very recently, the administration of pegIFN $\alpha$ and ribavirin for 6 to 12 months had been the standard of care before using DAAs. During this evolution of treatment options, the SVR rates have increased from the $15 \%$ to $20 \%{ }^{28,29}$ by the IFN $\alpha$ monotherapy to over $90 \%$ by the DAA treatments.

The first DAAs, which were approved in 2011 for use in the treatment of chronic hepatitis $\mathrm{C}$, were boceprevir (Merck) and telaprevir (Vertex), both NS3 protease inhibitors. These DAAs were not used by themselves, but used with pegIFN $\alpha$ and ribavirin as triple therapy due to the occurrence of resistant mutations. Despite some toxicity issues, an improved SVR of approximately 75\% was achieved by this therapy for genotype 1 HCV-infected patients. ${ }^{30,31}$ Since the approval of these NS3 protease inhibitors for the treatment of chronic hepatitis $\mathrm{C}$, more DAAs have been approved and are still being tested in clinical trials. Currently, three different viral proteins (NS3, NS5A, and NS5B) are the major targets of DAAs and interferon-free, alloral regimens are expected to be the standard of care in most of chronic hepatitis $\mathrm{C}$ treatments due to the severe side effects and poor tolerability of interferon treatment. However, antiviral drug resistance has become an issue again as was experienced in the treatment of other chronic viral diseases. From in vivo and in vitro data, the profiles of various resistant mutations against the DAA treatments have already been well documented (Fig. 2). ${ }^{32}$ Currently, most of DAA therapies are dual or triple therapy combining DAAs from different classes with or without ribavirin in order to minimize the occurrence of resistant mutations.

\section{NS3}

NS3 protein has two known enzymatic activities: serine protease and helicase. Most of DAAs targeting this protein act as protease inhibitors. Thus, one main mechanism of action of this class of DAAs is inhibition of proteolytic cleavage of viral proteins from NS3 to NS5B, which eventually suppresses viral RNA replication. Among the currently available NS3-targeting DAAs, boceprevir and telaprevir were approved for clinical use for the first time, which were followed by simeprevir, asunaprevir, and paritaprevir. Several antiviral-resistant mutations are frequently observed, for example, at V36, V55, R155, and D168 of NS3 protein (Table 1, Fig. 2). Interestingly, when the viral fitness of the resistant mutations was assessed using the in vitro cell culture system, many resistant mutations showed defects in viral RNA replication while some (e.g., R155T) showed more severe defects in infectious virus production, ${ }^{33}$ thus suggesting a potential role of NS3 protease in virus assembly.

\section{NS5A}

NS5A protein has no known enzymatic activity but is impor-

NS3 protease (180 amino acids)

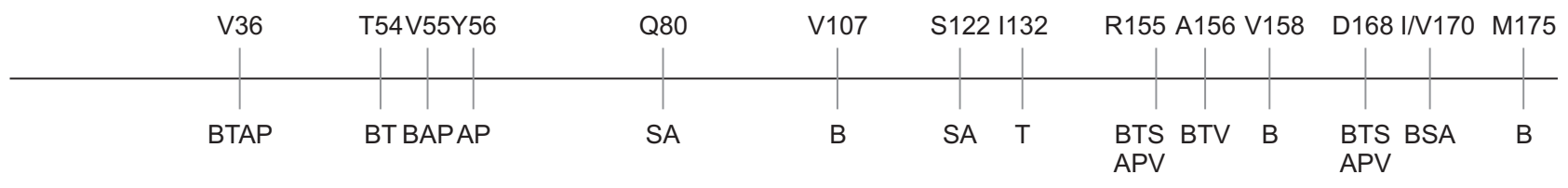

NS5A domain 1 (213 amino acids)

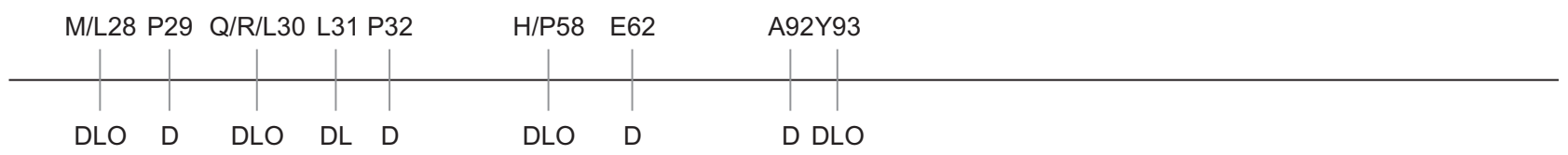

NS5B (591 amino acids)

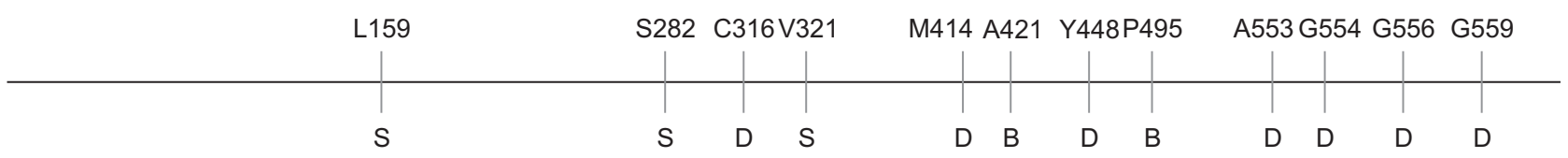

Fig. 2. Antiviral-resistant mutations of NS3 protease, NS5A and NS5B RNA-dependent RNA polymerase. The resistance-associated amino acids are located with the corresponding direct-acting antivirals that select these resistances: NS3 (B, boceprevir; T, telaprevir; S, simeprevir; A, asunaprevir; P, paritaprevir; and V, vaniprevir), NS5A (D, daclatasvir; L, ledipasvir; and 0, ombitasvir) and NS5B (S, sofosbuvir; D, dasabuvir; and B, beclabuvir). Note that sofosbuvir is a nucleotide inhibitor, whereas dasabuvir and beclabuvir are nonnucleoside inhibitors. 
Table 1. Most Commonly Observed NS3-Resistant Mutations ${ }^{32}$

\begin{tabular}{lll}
\hline Inhibitor & \multicolumn{1}{c}{ Genotype 1a } & \multicolumn{1}{c}{ Genotype 1b } \\
\hline Boceprevir & V36M, T54S, R155K & T54A/S, V55A, A156S, V170A \\
Telaprevir & V36M, R155K & V36A, T54A, A156S \\
Simeprevir & R155K, D168E/V & Q80R, D168E/V \\
Asunaprevir & R155K, D168E & D168E/V/Y \\
Paritaprevir & D168A/V/Y & Y56H, D168V \\
Vaniprevir & R155K, D168T/V/Y & D168H/T/V \\
\hline
\end{tabular}

Table 2. Most Commonly Observed NS5A-Resistant Mutations ${ }^{32}$

\begin{tabular}{cll}
\hline Inhibitor & \multicolumn{1}{c}{ Genotype 1a } & Genotype 1b \\
\hline Daclatasvir & M28T, Q30E/H/R, L31M, H58D, Y93H/N & L31M/V, Y93H \\
Ledipasvir & Q30E/R, L31M, Y93C/H/N & Y93H \\
Ombitasvir & M28T, Q30R & Y93H \\
\hline
\end{tabular}

tant for both viral RNA replication and assembly of infectious virus particles. NS5A protein is composed of an N-terminal amphipathic $\alpha$-helix that associates with the cellular membrane and three consecutive domains (domain 1 to 3 ). The domains 1 and 2 are important for viral RNA replication while the domain 3 is indispensable for virus assembly. ${ }^{34-37}$ Daclatasvir (BristolMyers Squibb), the first NS5A-targeting DAA, was discovered during the small molecule library screening using the genotype 1b Con 1 replicon cell line. ${ }^{38}$ The inhibitory potency of daclatasvir was outstanding but this inhibitor also selected resistant mutations such as Y93H and L31V (Fig. 2). In fact, the presence of these resistant mutations is known as the key determinant of the success of daclatasvir + asunaprevir dual therapy. ${ }^{39}$ In the presence of these mutations, the SVR for the daclatasvir + asunaprevir dual therapy was less than $50 \% .^{39}$ So far, all known resistant mutations of NS5A were identified in the domain 1 (Table 2, Fig. 2). A recent kinetic analysis of DAAs from the different classes found that NS5A inhibitors restrict two distinct steps of HCV life cycle: replication complex formation and virus assembly. ${ }^{40}$ Interestingly, NS5A protein exists as a dimer, which is also suggested by the symmetrical structure of daclatasvir. ${ }^{41}$

\section{NS5B}

NS5B protein is an RNA-dependent RNA polymerase, a key enzyme which directly catalyzes the synthesis of plus- and minus-strand of viral RNAs. This protein is a highly error-prone enzyme since it does not have the proofreading capability. Depending on the inhibition modes, NS5B inhibitors are classified into either nucleotide analogs (e.g., sofosbuvir) or nonnucleoside analogs (e.g., dasabuvir, beclabuvir), the latter of which act as allosteric inhibitors. Of these inhibitors, sofosbuvir (Gilead) is particularly interesting in that it showed excellent SVRs in numerous clinical trials and a very high genetic barrier to resistance development. This unique property of sofosbuvir has
Table 3. Most Commonly Observed NS5B-Resistant Mutations ${ }^{32}$

\begin{tabular}{clc}
\hline Inhibitor & Genotype 1a & Genotype 1b \\
\hline Dasabuvir & M414T, S556G & S556G \\
Baclabuvir & A421V, P495L/S & None \\
\hline
\end{tabular}

made it the first choice of DAA for several all-oral regimens for treatment of chronic hepatitis C. Despite its outstanding profiles as an antiviral agent, the cost is still an issue in many countries. Several resistance-associated mutations of NS5B are located in Fig. 2 and the most commonly observed NS5B resistant mutations are summarized in Table 3. Interestingly, no cross-resistance was observed between the nucleotide and nonnucleoside inhibitors due to the different mechanisms and sites of interaction with NS5B.

\section{CONCLUSIONS}

Substantial progresses in the development of antiviral therapies have increased the sustained virological response and now approximately $90 \%$ to $95 \%$ of chronic hepatitis C patients are expected to be cured, thus significantly reducing the number of more complicating liver diseases such as cirrhosis and hepatocellular carcinoma. Although this is a remarkable accomplishment and the first in the human history in that the chronic viral infection is curable, still the 5\% to $10 \%$ of the chronic hepatitis $\mathrm{C}$ patients are suffering from this viral infection and awaiting better treatment options. In addition, more cases of antiviral drug resistance are being reported and the retreatment of the patients who have failed in the prior antiviral treatments is the issue that has to be immediately addressed.

In terms of virology, HCV was discovered relatively later than the other closely related viruses belonging to the family Flaviviridae (e.g., dengue virus, Japanese encephalitis virus, 
West Nile virus, yellow fever virus, etc.). However, the significant global impact of HCV infection has far more advanced virology of this specific virus and the knowledge that was obtained from the study of HCV would accelerate a better understanding of the other clinically important flaviviruses. In addition, it would also lead to the development of new antiviral therapies to eradicate these deadly human pathogens.

\section{CONFLICTS OF INTEREST}

No potential conflict of interest relevant to this article was reported.

\section{REFERENCES}

1. Alter HJ, Holland PV, Morrow AG, Purcell RH, Feinstone SM, Moritsugu Y. Clinical and serological analysis of transfusionassociated hepatitis. Lancet 1975;2:838-841.

2. Feinstone SM, Kapikian AZ, Purcell RH, Alter HJ, Holland PV. Transfusion-associated hepatitis not due to viral hepatitis type A or B. N Engl J Med 1975;292:767-770.

3. Choo QL, Kuo G, Weiner AJ, Overby LR, Bradley DW, Houghton $\mathrm{M}$. Isolation of a cDNA clone derived from a blood-borne non-A, non-B viral hepatitis genome. Science 1989;244:359-362.

4. Lohmann V, Körner F, Koch J, Herian U, Theilmann L, Bartenschlager R. Replication of subgenomic hepatitis C virus RNAs in a hepatoma cell line. Science 1999;285:110-113.

5. Wakita T, Pietschmann T, Kato T, et al. Production of infectious hepatitis $\mathrm{C}$ virus in tissue culture from a cloned viral genome. Nat Med 2005;11:791-796.

6. Lemon SM, Walker CM, Alter MJ, Yi M. Hepatitis C virus. In: Knipe DM, Howley PM, Griffin DE, et al, eds. Fields virology. Volume 1. 5th ed. Philadelphia: Lippincott Williams and Wilkins, 2007:1253-1304.

7. Ding Q, von Schaewen M, Ploss A. The impact of hepatitis C virus entry on viral tropism. Cell Host Microbe 2014;16:562-568.

8. Paul D, Madan V, Bartenschlager R. Hepatitis C virus RNA replication and assembly: living on the fat of the land. Cell Host Microbe 2014;16:569-579.

9. Miyanari Y, Atsuzawa K, Usuda N, et al. The lipid droplet is an important organelle for hepatitis C virus production. Nat Cell Biol 2007;9:1089-1097.

10. Huang H, Sun F, Owen DM, et al. Hepatitis C virus production by human hepatocytes dependent on assembly and secretion of very low-density lipoproteins. Proc Natl Acad Sci U S A 2007;104:58485853.

11. Gastaminza P, Cheng G, Wieland S, Zhong J, Liao W, Chisari FV. Cellular determinants of hepatitis C virus assembly, maturation, degradation, and secretion. J Virol 2008;82:2120-2129.

12. Yi M, Lemon SM. Adaptive mutations producing efficient replication of genotype 1a hepatitis C virus RNA in normal Huh7 cells. J Virol 2004;78:7904-7915.
13. Blight KJ, Kolykhalov AA, Rice CM. Efficient initiation of HCV RNA replication in cell culture. Science 2000;290:1972-1974.

14. Saeed M, Scheel TK, Gottwein JM, et al. Efficient replication of genotype 3a and 4a hepatitis C virus replicons in human hepatoma cells. Antimicrob Agents Chemother 2012;56:5365-5373.

15. Saeed M, Gondeau C, Hmwe S, et al. Replication of hepatitis C virus genotype 3a in cultured cells. Gastroenterology 2013;144:5658.e7.

16. Peng B, Yu M, Xu S, et al. Development of robust hepatitis $\mathrm{C}$ virus genotype 4 subgenomic replicons. Gastroenterology 2013;144:5961.e6.

17. Wose Kinge CN, Espiritu C, Prabdial-Sing N, Sithebe NP, Saeed M, Rice CM. Hepatitis $\mathrm{C}$ virus genotype $5 \mathrm{a}$ subgenomic replicons for evaluation of direct-acting antiviral agents. Antimicrob Agents Chemother 2014;58:5386-5394.

18. Yu M, Peng B, Chan K, et al. Robust and persistent replication of the genotype $6 a$ hepatitis $\mathrm{C}$ virus replicon in cell culture. Antimicrob Agents Chemother 2014;58:2638-2646

19. Bartosch B, Dubuisson J, Cosset FL. Infectious hepatitis C virus pseudo-particles containing functional E1-E2 envelope protein complexes. J Exp Med 2003;197:633-642.

20. Yi M, Villanueva RA, Thomas DL, Wakita T, Lemon SM. Production of infectious genotype 1a hepatitis $\mathrm{C}$ virus (Hutchinson strain) in cultured human hepatoma cells. Proc Natl Acad Sci U S A 2006;103:2310-2315.

21. Li YP, Ramirez S, Jensen SB, Purcell RH, Gottwein JM, Bukh J. Highly efficient full-length hepatitis $C$ virus genotype 1 (strain TN) infectious culture system. Proc Natl Acad Sci U S A 2012;109:19757-19762.

22. Yamane D, McGivern DR, Wauthier E, et al. Regulation of the hepatitis C virus RNA replicase by endogenous lipid peroxidation. Nat Med 2014;20:927-935.

23. Kim S, Date T, Yokokawa H, et al. Development of hepatitis C virus genotype 3a cell culture system. Hepatology 2014;60:18381850.

24. Heim MH. 25 Years of interferon-based treatment of chronic hepatitis C: an epoch coming to an end. Nat Rev Immunol 2013;13:535542

25. McHutchison JG, Gordon SC, Schiff ER, et al. Interferon alfa$2 \mathrm{~b}$ alone or in combination with ribavirin as initial treatment for chronic hepatitis C: Hepatitis Interventional Therapy Group. N Engl J Med 1998;339:1485-1492.

26. Manns MP, McHutchison JG, Gordon SC, et al. Peginterferon alfa$2 \mathrm{~b}$ plus ribavirin compared with interferon alfa- $2 \mathrm{~b}$ plus ribavirin for initial treatment of chronic hepatitis C: a randomised trial. Lancet 2001;358:958-965.

27. Fried MW, Shiffman ML, Reddy KR, et al. Peginterferon alfa-2a plus ribavirin for chronic hepatitis C virus infection. N Engl J Med 2002;347:975-982.

28. Lin R, Roach E, Zimmerman M, Strasser S, Farrell GC. Interferon alfa-2b for chronic hepatitis C: effects of dose increment and duration of treatment on response rates: results of the first multicen- 
tre Australian trial. Australia Hepatitis C Study Group. J Hepatol 1995;23:487-496.

29. Poynard T, Bedossa P, Chevallier M, et al. A comparison of three interferon alfa-2b regimens for the long-term treatment of chronic non-A, non-B hepatitis: Multicenter Study Group. N Engl J Med 1995;332:1457-1462.

30. Poordad F, McCone J Jr, Bacon BR, et al. Boceprevir for untreated chronic HCV genotype 1 infection. N Engl J Med 2011;364:11951206.

31. Jacobson IM, McHutchison JG, Dusheiko G, et al. Telaprevir for previously untreated chronic hepatitis $\mathrm{C}$ virus infection. $\mathrm{N}$ Engl $\mathrm{J}$ Med 2011;364:2405-2416.

32. Lontok E, Harrington P, Howe A, et al. Hepatitis C virus drug resistance-associated substitutions: state of the art summary. Hepatology 2015;62:1623-1632.

33. Shimakami T, Welsch C, Yamane D, et al. Protease inhibitor-resistant hepatitis $\mathrm{C}$ virus mutants with reduced fitness from impaired production of infectious virus. Gastroenterology 2011;140:667675.

34. Appel N, Zayas M, Miller S, et al. Essential role of domain III of nonstructural protein $5 \mathrm{~A}$ for hepatitis $\mathrm{C}$ virus infectious particle assembly. PLoS Pathog 2008;4:e1000035.

35. Tellinghuisen TL, Foss KL, Treadaway J. Regulation of hepatitis C virion production via phosphorylation of the NS5A protein. PLoS Pathog 2008;4:e1000032.

36. Masaki T, Suzuki R, Murakami K, et al. Interaction of hepatitis $C$ virus nonstructural protein $5 \mathrm{~A}$ with core protein is critical for the production of infectious virus particles. J Virol 2008;82:79647976.

37. Kim S, Welsch C, Yi M, Lemon SM. Regulation of the production of infectious genotype 1a hepatitis C virus by NS5A domain III. J Virol 2011;85:6645-6656.

38. Gao M, Nettles RE, Belema M, et al. Chemical genetics strategy identifies an HCV NS5A inhibitor with a potent clinical effect. Nature 2010;465:96-100.

39. Karino Y, Toyota J, Ikeda K, et al. Characterization of virologic escape in hepatitis $\mathrm{C}$ virus genotype $1 \mathrm{~b}$ patients treated with the direct-acting antivirals daclatasvir and asunaprevir. J Hepatol 2013;58:646-654.

40. McGivern DR, Masaki T, Williford S, et al. Kinetic analyses reveal potent and early blockade of hepatitis C virus assembly by NS5A inhibitors. Gastroenterology 2014;147:453-462.e7.

41. Tellinghuisen TL, Marcotrigiano J, Rice CM. Structure of the zincbinding domain of an essential component of the hepatitis $C$ virus replicase. Nature 2005;435:374-379. 